\title{
(2) OPEN ACCESS \\ Neurodevelopmental outcome of patients with congenital gastrointestinal malformations: a systematic review and meta-analysis
}

\author{
Daniëlle Roorda ำ ${ }^{1,2}$ Marsh Königs, ${ }^{2}$ Laurens Eeftinck Schattenkerk, ${ }^{1}$ \\ Lideke van der Steeg, ${ }^{1,3}$ Ernest van Heurn, ${ }^{1}$ Jaap Oosterlaan ${ }^{2}$
}

\begin{abstract}
- Additional supplemental material is published online only. To view, please visit the journal online (http://dx.doi. org/10.1136/archdischild2021-322158)
\end{abstract}

For numbered affiliations see end of article.

\section{Correspondence to}

Daniëlle Roorda, Department of Pediatric Surgery, Amsterdam Reproduction and Development Research Institute, Emma Children's Hospital, Amsterdam UMC, Amsterdam 1105 AZ, The Netherlands;

d.roorda@amsterdamumc.n

The findings of this study have been presented in a poster presentation at the 20th European Congress of Pediatric Surgery of the European Pediatric Surgical Association (EUPSA) in Belgrade.

Received 29 March 2021 Accepted 12 April 2021 Published Online First 10 June 2021

\section{ABSTRACT}

Aim Children with congenital gastrointestinal malformations may be at risk of neurodevelopmental impairment due to challenges to the developing brain, including perioperative haemodynamic changes, exposure to anaesthetics and postoperative inflammatory influences. This study aggregates existing evidence on neurodevelopmental outcome in these patients using meta-analysis.

Method PubMed, Embase and Web of Science were searched for peer-reviewed articles published until October 2019. Out of the 5316 unique articles that were identified, 47 studies met the inclusion criteria and were included. Standardised mean differences (Cohen's d) between cognitive, motor and language outcome of patients with congenital gastrointestinal malformations and normative data (39 studies) or the studies' control group (8 studies) were aggregated across studies using random-effects meta-analysis. The value of (clinical) moderators was studied using meta-regression and diagnostic subgroups were compared.

Results The 47 included studies encompassed 62 cohorts, representing 2312 patients. Children with congenital gastrointestinal malformations had smallsized cognitive impairment $(d=-0.435, p<0.001 ; 95 \% \mathrm{Cl}$ -0.567 to -0.302$)$, medium-sized motor impairment $(d=-0.610, p<0.001 ; 95 \% \mathrm{Cl}-0.769$ to -0.451$)$ and medium-sized language impairment $(\mathrm{d}=-0.670$, $\mathrm{p}<0.001 ; 95 \% \mathrm{Cl}-0.914$ to -0.425$)$. Patients with short bowel syndrome had worse motor outcome. Neurodevelopmental outcome was related to the number of surgeries and length of total hospital stay, while no relations were observed with gestational age, birth weight, age and sex.

Interpretation This study shows that children with congenital gastrointestinal malformations exhibit impairments in neurodevelopmental outcome, highlighting the need for routine screening of neurodevelopment during follow-up.

\section{INTRODUCTION}

Congenital gastrointestinal malformations (ie, oesophageal atresia, gastroschisis, omphalocele, intestinal atresia, Hirschsprung's disease and anorectal malformations) are relatively uncommon conditions with a total prevalence of about 15 per 10000 European births a year. ${ }^{1}$ Although survival in these patients has improved over the past decades, morbidity remains high. ${ }^{2-8}$ Recent evidence suggests

\section{What is already known on this topic?}

- Patients with non-cardiac congenital malformations are at risk of motor and cognitive impairment up to the age of 2 years.

- Patients with gastrointestinal malformations are subject to several potential aetiological factors contributing to negative impact on the developing brain.

\section{What this study adds?}

- Patients with congenital gastrointestinal malformations have impaired neurodevelopmental outcome up to adolescence.

- Cognitive impairment was small-sized, whereas motor and language impairment was medium-sized.

- Impairment was related to length of hospital stay and number of surgeries.

that there may also be an impact on the central nervous system of these patients. ${ }^{9}$

The available literature provides evidence for several pathways implicated in congenital gastrointestinal malformations that may contribute to a negative impact on the developing central nervous system: (1) genetic abnormalities ${ }^{10}{ }^{11}$; (2) perinatal influences, such as maternal smoking, ${ }^{12}$ use of medication, ${ }^{13}{ }^{14}$ preterm birth ${ }^{15}$ and low birth weight ${ }^{15}$; (3) early, long and/or repeated exposure to anaesthetics necessary for surgical correction(s) ${ }^{16-18}$; (4) perioperative haemodynamics and respiratory functioning ${ }^{19-21}$; (5) postoperative inflammatory challenges $^{22} 23$; and (6) poor nutritional status that can lead to an altered microbiome, influencing the developing brain through the gut-brain axis. ${ }^{24-27}$ All these harmful challenges to the central nervous system may lead to neurodevelopmental impairment, which in turn may interfere with development in important domains of functioning, including academic achievement, behavioural functioning, and social and economic well-being. ${ }^{28-30}$

The primary aim of the current systematic review is to quantitatively aggregate all available empirical evidence on the effects of having a congenital gastrointestinal malformation on neurodevelopment using 
meta-analysis. This review focuses on congenital gastrointestinal malformations other than congenital diaphragmatic hernia $(\mathrm{CDH})$, to not include the confounding effect of the pulmonary comorbidity in patients with $\mathrm{CDH},{ }^{31-33}$ which may require treatment with extracorporeal membrane oxygenation. ${ }^{345}$ The secondary aim is to study differences between specific types of congenital gastrointestinal malformations and the contribution of possible moderating factors for neurodevelopmental impairment, using meta-regression.

\section{METHODS}

This study was performed according to the Preferred Reporting Items for Systematic Reviews and Meta-Analyses guidelines (see online supplemental material). ${ }^{36}$

\section{Search and selection}

The search strategy combined three groups of search terms and their equivalents: (1) terms related to the congenital malformations of interest, (2) terms defining age groups, (3) terms defining (the validated measures of) the outcomes. The full search strategy can be found in the online supplemental material. PubMed, Embase and Web of Science were searched using both simple search terms and hierarchical family forms (eg, Medical Subject Headings, Thesaurus, Emtree). The reference lists of eligible articles were also screened for additional articles. The last search was conducted in October 2019.

A flow diagram of the study search and selection is provided in figure 1. A total of 6675 records were identified corresponding to 5316 unique articles. Two authors (DR and LES) independently assessed each article for eligibility using Covidence, an online tool for systematic reviews. ${ }^{37}$ Conflicts in the selection process were solved by consensus, or a third party was consulted.

\section{Inclusion criteria}

Studies were included in this systematic review and metaanalysis if they: (1) included patients with a congenital gastrointestinal malformation (ie, oesophageal atresia, omphalocele, gastroschisis, intestinal atresia, Hirschsprung's disease, anorectal malformations and short bowel syndrome), excluding $\mathrm{CDH},(2)$ included subjects within the age range from infancy to adolescence (0-18 years), (3) reported cognitive, motor or language outcome measured with any standardised and/or validated measure, compared with a selected control group or normative population, (4) used an observational or controlled design, (5) were published in a peer-reviewed journal, (6) were published after 1990, and (7) were written in the English language. Studies reporting on adults only, or studies reporting on both children and adults without detailing the results for only children, were excluded, as well as review papers and case reports. A cohort was defined as a subgroup of the total group of patients included in a study, mostly defined in terms of a particular congenital malformation, and in few studies defined in terms of age at follow-up. How selection was done in case multiple studies reported on (partly) overlapping cohorts is described in the online supplemental material. Authors of studies were contacted in case a study did not report all data required for the planned analyses. In total, 47 studies were included in the meta-analysis. A reference list is provided in the online supplemental material.

\section{Data extraction}

The following data were extracted by two authors (DR and LES): (1) mean raw or standardised scores, accompanying SDs and sample sizes for all outcome measures were extracted for all separate cohorts of cases and, if applicable, control groups. If this information was not available, the proportion of individuals with neurodevelopmental outcome in the standardised normal range was compared between patients and the normative or control sample, in which case sample sizes and relevant p values were extracted. (2) Study characteristics, including: sample sizes, type(s) of malformation(s) assessed, instrument(s) used to assess neurodevelopment, length of follow-up, attrition of the study sample at follow-up; and (3) potential (clinical) moderating factors of neurodevelopmental outcome (listed in online supplemental material tables 1 and 3 ).

\section{Quality assessment}

Quality of the included studies was independently assessed by two authors (DR and LES) using the Newcastle-Ottawa Scale (NOS), based on selection of subjects (4 points), comparability of patient and control groups (2 points) and outcome measurements (3 points). ${ }^{38}$ 39 Adjustments to the tool according to the manual and scoring methods are described in the online supplemental material. Rating discrepancies were resolved by consensus.

\section{Statistics}

Analyses were performed using Comprehensive MetaAnalysis (CMA) software (V.3.0, Biostat). Using the extracted mean (SD) of raw or standardised scores on cognitive, motor and/or language outcome of cases, and of controls (8 studies) or normative data (39 studies), we calculated effect sizes as the standardised mean difference (Cohen's d) between groups. Outcome measures in the current metaanalyses were: overall neurodevelopmental outcome and three domains of neurodevelopmental outcome: cognitive outcome, motor outcome and language outcome. Overall

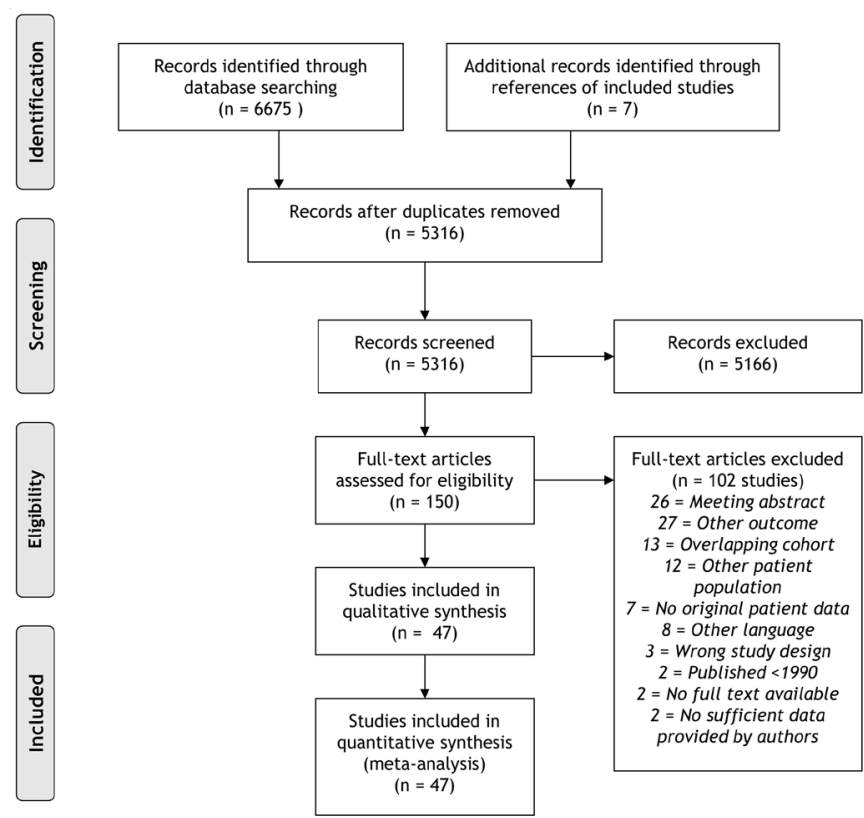

Figure 1 Preferred Reporting Items for Systematic Reviews and MetaAnalyses flow chart. 


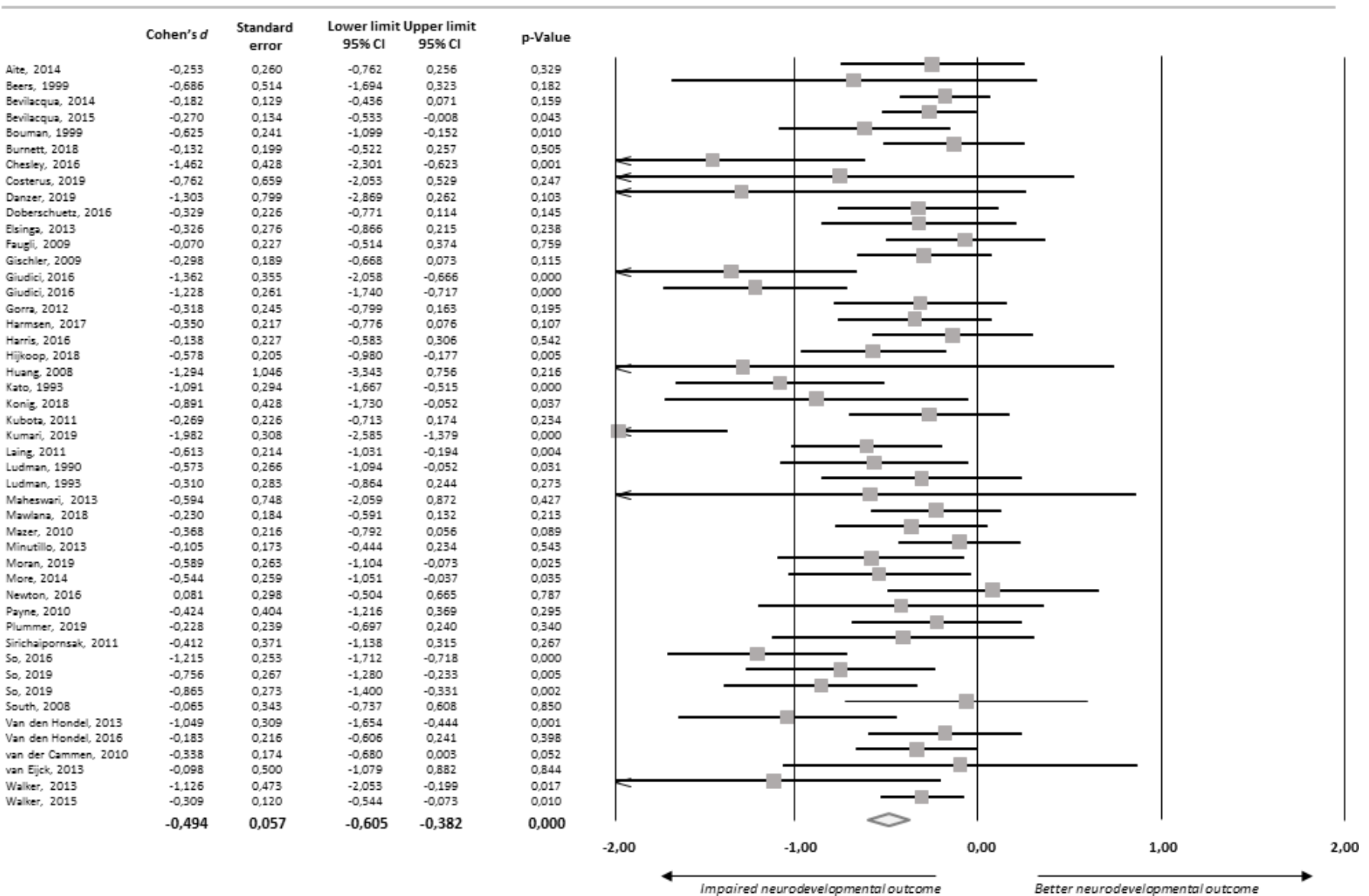

Figure 2 Forest plot of standardised mean differences in overall neurodevelopmental outcome.

neurodevelopmental outcome was calculated on a study level by using the built-in function of CMA, which generates the weighted average of study findings across domains (motor, cognitive and/or language outcome). The individual study's effect sizes were subsequently aggregated across studies into meta-analytical effect sizes using the random-effects model to account for heterogeneity introduced by the included range of outcome measures, diagnostic subgroups and age groups. These analyses were rerun, excluding studies that may have included subjects with chromosomal abnormalities, to eliminate the influence of neurodevelopmental impairment related to a syndrome. In case of statistical significant difference in overall neurodevelopmental outcome, differences between the meta-analytical findings for cognitive, motor and language outcome were further explored using subgroup comparisons. If a meta-analytical effect size was built up by a minimum of 10 individual studies' effect sizes, we explored possible moderating effects on the outcomes using univariate meta-regression with a random-effects model. For cohorts that were assessed at multiple assessment points, a weighted average was calculated for the moderator variables at study level and used in meta-regression to calculate the relationship

Table 1 Meta-analytical findings for neurodevelopment in children with congenital gastrointestinal malformations

\begin{tabular}{|c|c|c|c|c|c|c|c|}
\hline & $\begin{array}{l}\text { Number of } \\
\text { studies }\end{array}$ & $\begin{array}{l}\text { Number of } \\
\text { observations }\end{array}$ & Cohen's d (95\% Cl, p value) & $\begin{array}{l}\text { Difference between } \\
\text { findings on domains of } \\
\text { neurodevelopmental } \\
\text { outcome }\end{array}$ & $\begin{array}{l}\text { Heterogeneity, } \\
\mathrm{I}^{2}\end{array}$ & Significant moderators & $\begin{array}{l}\text { Egger's } \\
\text { intercept }\end{array}$ \\
\hline $\begin{array}{l}\text { Overall } \\
\text { neurodevelopmental } \\
\text { outcome }\end{array}$ & 47 & 2312 & $\begin{array}{l}-0.494 \\
(-0.605 \text { to }-0.382, p<0.001)\end{array}$ & & $56.2 \%$ & $\begin{array}{l}\text { Mean length of stay: } \\
b=-0.005, p<0.001 \text {, mean } \\
\text { number of surgeries: } \\
b=-0.1371, p=0.003\end{array}$ & $\begin{array}{l}-1.874 \\
p<0.001\end{array}$ \\
\hline Cognitive outcome & 39 & 2055 & $\begin{array}{l}-0.435 \\
(-0.567 \text { to }-0.302, p=<0.001)\end{array}$ & $Q=3.194, p=0.343$ & $63.7 \%$ & $\begin{array}{l}\text { Mean number of surgeries: } \\
b=-0.0825, p=0.045\end{array}$ & $\begin{array}{l}-0.711 \\
p=0.031\end{array}$ \\
\hline Motor outcome & 33 & 1821 & $\begin{array}{l}-0.610 \\
(-0.769 \text { to }-0.451, p=<0.001)\end{array}$ & & $70.3 \%$ & $\begin{array}{l}\text { Mean length of stay: } \\
b=-0.005, p=0.008 \text {, mean } \\
\text { number of surgeries: } \\
b=-0.1789, p=0.001\end{array}$ & $\begin{array}{l}-2.502 \\
p<0.001\end{array}$ \\
\hline Language outcome & 14 & 701 & $\begin{array}{l}-0.670 \\
(-0.914 \text { to }-0.425, p=<0.001)\end{array}$ & & $68.4 \%$ & - & $\begin{array}{l}-2.743 \\
p=0.013\end{array}$ \\
\hline
\end{tabular}




\begin{tabular}{|c|c|c|c|}
\hline Type of malformation & Number of studies & $\begin{array}{l}\text { Cohen's } d(95 \% \mathrm{Cl}, \mathrm{p} \text { value) on overall } \\
\text { neurodevelopmental outcome }\end{array}$ & $\begin{array}{l}\text { Type of malformation versus other } \\
\text { types of malformation, } Q \text {-values, } p \\
\text { values }\end{array}$ \\
\hline Abdominal wall defects (ie, gastroschisis, omphalocele) & 17 & $-0.375(-0.567$ to $-0.182, p<0.001)$ & $\mathrm{Q}=1.14, \mathrm{p}=0.286$ \\
\hline $\begin{array}{l}\text { Colorectal malformations (ie, Hirschsprung's disease, } \\
\text { anorectal malformations) }\end{array}$ & 10 & $-0.485(-0.765$ to $-0.206, p=0.001)$ & $\mathrm{Q}=0.024, \mathrm{p}=0.877$ \\
\hline Oesophageal atresia & 17 & $-0.521(-0.713$ to $-0.328, p<0.001)$ & $\mathrm{Q}=0.433, \mathrm{p}=0.506$ \\
\hline Intestinal atresia & 5 & $-0.251(-0.585$ to $-0.082, p=0.140)$ & $Q=1.657, p=0.190$ \\
\hline Short bowel syndrome & 6 & $-1.000(-1.324$ to $-0.675, \mathrm{p}<0.001)$ & $Q=11.639, p=0.002$ \\
\hline
\end{tabular}

with the weighted average effect sizes of outcome data (Cohen's d) at study level. When studies reported the median with IQRs, means and SD were calculated. ${ }^{40}{ }^{41}$ Furthermore, subgroup comparisons were performed to test for possible differences between diagnostic subgroups (ie, different types of malformations) and domains of outcome. Effect sizes were interpreted as small $(\mathrm{d}=0.2-0.5)$ medium $(\mathrm{d}=0.5-0.8)$ or large $(\mathrm{d} \geq 0.8)$, according to Cohen. ${ }^{42}$ Heterogeneity was interpreted as small $\left(\mathrm{I}^{2} \leq 0.25\right)$, medium $\left(\mathrm{I}^{2}=0.25-0.50\right)$ or strong $\left(\mathrm{I}^{2} \geq 0.50\right)$, according to Higgins. ${ }^{43}$ The possibility of publication bias was assessed by visual inspection of Funnel plots and by calculating Funnel plot asymmetry expressed as the Egger's regression intercept $t .{ }^{44}$ To test for bias caused by studies with a fair or poor quality of design, sensitivity analyses were conducted on studies of good quality only.

\section{RESULTS}

Sample description

This systematic review and meta-analysis represents a total of 2312 patients described in 47 studies (online supplemental table 1). A detailed sample description in terms of distribution of types of malformation, sex, age groups, birth weight and gestational age can be found in the online supplemental material.

\section{Overall neurodevelopmental outcome}

The meta-analysis on overall neurodevelopmental outcome included all 47 studies ( $n=2312$ patients; figure 2$)$. Nineteen of the 47 studies showed significantly poorer overall neurodevelopmental outcome of patients with congenital gastrointestinal malformations compared with normative data or healthy controls. Meta-analytical aggregation of all findings showed a small-sized negative effect on overall neurodevelopmental outcome $(\mathrm{d}=-0.494, \mathrm{p}<0.001 ; 95 \%$ CI -0.605 to $-0.382, \mathrm{I}^{2}=56.2 \%$; table 1$)$.

\section{Cognitive outcome}

The meta-analysis on cognitive outcome included 39 studies ( $n=2055$ patients). In 12 of the 39 studies, cognitive outcome of patients with congenital gastrointestinal malformations was significantly worse compared with normative data or healthy controls. Meta-analytical aggregation showed a small-sized negative effect on cognitive outcome $(\mathrm{d}=-0.435, \mathrm{p}<0.001 ; 95 \%$ CI -0.567 to -0.302 , $\mathrm{I}^{2}=63.7 \%$; table 1$)$.

\section{Motor outcome}

The meta-analysis on motor outcome included 33 studies ( $n=1821$ patients). In 14 of 33 studies, motor outcome of patients with congenital gastrointestinal malformation was significantly worse compared with the normative population or healthy controls. Meta-analytical aggregation showed a medium-sized negative effect on motor outcome $(\mathrm{d}=-0.610$, $\mathrm{p}<0.001 ; 95 \% \mathrm{CI}-0.769$ to $-0.451, \mathrm{I}^{2}=70.3 \%$; table 1 ).

\section{Language outcome}

The meta-analysis on language outcome included 14 studies ( $n=701$ patients). Ten out of 14 studies showed a significant negative difference between language development of patients with a congenital gastrointestinal malformation and the normative population or healthy controls. Metaanalytical aggregation showed a medium-sized negative effect $(\mathrm{d}=-0.670, \mathrm{p}<0.001 ; 95 \% \mathrm{CI}-0.914$ to -0.425 , $\mathrm{I}^{2}=68.4 \%$; table 1$)$.

Influence of possible presence of chromosomal abnormalities Sensitivity analyses excluding three studies that may have included subjects with chromosomal abnormalities showed comparable (if not larger) impairments on overall neurodevelopmental outcome $(\mathrm{d}=-0.519, \mathrm{p}<0.001)$, cognitive outcome $(\mathrm{d}=-0.458, \mathrm{p}<0.001)$, motor outcome $(\mathrm{d}=-0.658, \mathrm{p}<0.001)$ and language outcome $(\mathrm{d}=-0.780$, $\mathrm{p}<0.001)$.

\section{Meta-regression of possible moderators of neurodevelopmental outcome}

Meta-regression showed that worse overall neurodevelopmental and worse motor outcome were related to longer mean total length of hospital stay, worse overall neurodevelopmental, worse cognitive and worse motor outcome were related to a higher mean number of surgeries, while no relations were observed with mean age, mean gestational age, mean birth weight and percentage of boys in a study, as shown in table 1 and online supplemental table 2 .

\section{Differences between types of malformations}

When comparing meta-analytical effect sizes of subgroups of different types of malformations, we found a significant difference in the magnitude of effect sizes for overall neurodevelopment outcome $(\mathrm{Q}=11.52 ; \mathrm{p}=0.021)$ (table 2 ), that was traced down in further analyses to significantly poorer overall neurodevelopmental outcome for patients with short bowel syndrome compared with all remaining patient groups $(\mathrm{d}=-1.000$ and $\mathrm{d}=-0.412$, respectively, $\mathrm{Q}=11.639$; $\mathrm{p}=0.001)$. Further tests assessing differences between types of malformations are shown in the online supplemental material.

\section{Quality of studies and risk of bias analysis}

Results of the quality assessment are presented in table 3. NOS scores ranged from 4 to 9. Most studies had good 
Table 3 Quality of included studies as assessed with the Newcastle-Ottawa Scale (NOS)

\begin{tabular}{|c|c|c|c|c|c|}
\hline Study & $\begin{array}{l}\text { Selection of } \\
\text { subjects }\end{array}$ & $\begin{array}{l}\text { Comparability of cases } \\
\text { and controls }\end{array}$ & Outcome measurements & Total score* & Quality† \\
\hline Aite, $2014^{57}$ & 3 & 1 & 2 & 6 & Good \\
\hline Beers, $2000^{25}$ & 4 & 2 & 3 & 9 & Good \\
\hline Bevilacqua, $2014^{46}$ & 3 & 1 & 3 & 7 & Good \\
\hline Bevilacqua, $2015^{58}$ & 3 & 1 & 2 & 6 & Good \\
\hline Bouman, $1999^{65}$ & 3 & 1 & 2 & 6 & Good \\
\hline Burnett, $2018^{66}$ & 3 & 1 & 2 & 6 & Good \\
\hline Chesley, $2016^{26}$ & 3 & 1 & 3 & 7 & Good \\
\hline Costerus, $2019^{67}$ & 3 & 1 & 2 & 6 & Good \\
\hline Danzer, $2019^{62}$ & 3 & 1 & 2 & 6 & Good \\
\hline Doberschuetz, $2016^{68}$ & 4 & 2 & 3 & 9 & Good \\
\hline Elsinga, $2013^{49}$ & 3 & 1 & 2 & 6 & Good \\
\hline Faugli, $2009^{69}$ & 2 & 1 & 2 & 5 & Fair \\
\hline Gischler, $2009^{8}$ & 3 & 1 & 3 & 7 & Good \\
\hline Giudici, $2016^{70}$ & 3 & 0 & 3 & 6 & Poor \\
\hline Giudici, $2016^{71}$ & 3 & 0 & 2 & 5 & Poor \\
\hline Gorra, $2012^{72}$ & 3 & 2 & 2 & 7 & Good \\
\hline Harmsen, $2017^{59}$ & 3 & 1 & 3 & 7 & Good \\
\hline Harris, $2016^{73}$ & 3 & 1 & 2 & 6 & Good \\
\hline Hijkoop, $2017^{74}$ & 3 & 1 & 3 & 7 & Good \\
\hline Huang, $2008^{22}$ & 3 & 1 & 3 & 7 & Good \\
\hline Kato, $1993^{60}$ & 2 & 1 & 3 & 6 & Fair \\
\hline Konig, $2018^{75}$ & 2 & 1 & 3 & 6 & Fair \\
\hline Kubota, $2011^{47}$ & 2 & 1 & 2 & 5 & Fair \\
\hline Kumari, $2019^{76}$ & 3 & 0 & 1 & 4 & Poor \\
\hline Laing, $2011^{77}$ & 1 & 1 & 3 & 5 & Poor \\
\hline Ludman, $1990^{61}$ & 3 & 2 & 3 & 8 & Good \\
\hline Ludman, $1993^{78}$ & 3 & 2 & 3 & 8 & Good \\
\hline Maheshwari, $2013^{79}$ & 3 & 1 & 3 & 7 & Good \\
\hline Mazer, $2010^{3}$ & 3 & 1 & 3 & 7 & Good \\
\hline Mawlana, $2018^{80}$ & 3 & 1 & 3 & 7 & Good \\
\hline Minutillo, $2013^{81}$ & 3 & 1 & 3 & 7 & Good \\
\hline Moran, $2019^{82}$ & 3 & 2 & 2 & 7 & Good \\
\hline More, $2014^{83}$ & 3 & 1 & 2 & 6 & Good \\
\hline Newton, $2016^{84}$ & 4 & 2 & 2 & 8 & Good \\
\hline Payne, $2010^{85}$ & 4 & 2 & 3 & 9 & Good \\
\hline Plummer, $2019^{86}$ & 2 & 1 & 2 & 5 & Fair \\
\hline Sirichaipornsak, $2011^{87}$ & 3 & 1 & 2 & 6 & Good \\
\hline So, $2016^{88}$ & 3 & 1 & 3 & 7 & Good \\
\hline So, $2019^{89}$ & 2 & 1 & 2 & 5 & Fair \\
\hline So, $2019^{90}$ & 2 & 1 & 3 & 6 & Fair \\
\hline South, $2008^{91}$ & 3 & 1 & 3 & 7 & Good \\
\hline Van den Hondel, $2013^{92}$ & 3 & 1 & 3 & 7 & Good \\
\hline Van den Hondel, $2016^{93}$ & 3 & 1 & 3 & 7 & Good \\
\hline Van der Cammen-van Zijp, 2010 & 3 & 1 & 2 & 6 & Good \\
\hline Van Eijck, $2013^{50}$ & 3 & 1 & 2 & 6 & Good \\
\hline Walker, $2013^{94}$ & 3 & 2 & 3 & 8 & Good \\
\hline Walker, $2015^{95}$ & 3 & 2 & 2 & 7 & Good \\
\hline
\end{tabular}

*The NOS allows study quality of observational studies to be quantified on the basis of the methods used to select subjects (4 points), comparability of case and control groups ( 2 points) and outcome measurements (3 points).

tScores were converted to the Agency for Healthcare Research and Quality standards, in order to judge quality as 'good', 'fair' or 'poor'.

quality $(77 \%)$, with only a minority of studies qualifying as fair $(15 \%)$ or poor $(8 \%)$. Results of the sensitivity analysis on studies of good quality, risk of publication bias (see also table 1) and risk of other bias analyses are described in the online supplemental material.

\section{DISCUSSION}

This systematic review and meta-analysis of 47 studies representing 2012 patients revealed evidence for small-sized overall neurodevelopmental impairment in children with congenital gastrointestinal malformations compared with normative data or healthy controls, reflecting small-sized cognitive impairment, medium-sized motor impairment and medium-sized language impairment. These findings translate into an average difference in 6.5 IQ points and implicate a $3.6 \%$ increase in the number of children with cognitive delay, a $5.9 \%$ increase in the number of children with motor delay and $6.9 \%$ increase in the number of children with language delay. 
Excluding studies that may have included syndromal patients did not lead to altered conclusions. Our findings implicate that patients with congenital gastrointestinal malformations have increased risk of neurodevelopmental impairment. Our findings are in line with an earlier meta-analysis of cognitive and motor impairment in infants (up to 24 months of age) with non-cardiac congenital malformations ${ }^{45}$ although the slightly larger effects obtained in that metaanalysis may be explained by the inclusion of patients with $\mathrm{CDH}^{46}$

Robust evidence for neurodevelopmental impairment was found in all types of congenital gastrointestinal malformations. Contrary to what has been indicated in previous reports, ${ }^{4647}$ no differences in meta-analytical effect sizes of overall neurodevelopmental outcome were found between patients with specific types of congenital gastrointestinal malformations, except for relatively poorer overall neurodevelopment and motor development in patients with short bowel syndrome.

Considering moderating factors, the results revealed that longer mean length of stay and a higher mean number of surgeries were related to greater overall neurodevelopmental impairment and motor development. This may suggest that the more complex the course of disease and/or treatment that is required, the more profound the impact is on neurodevelopmental outcome. The results of our meta-regression analyses showed no differences in the magnitude of effect between the different age groups. This cross-sectional finding suggests that the magnitude of neurodevelopmental impairment remains relatively stable over developmental stages, but remains to be investigated by longitudinal studies.

Although preterm birth and low birth weight are associated with neurodevelopmental impairment, ${ }^{26}{ }^{48-54}$ meta-regression analyses found no evidence for the possibility that our findings reflect the effects of gestational age or birth weight. This suggests that other common aetiological factors for neurodevelopmental impairment may play a (more important) role in the neurodevelopmental impairments of patients with congenital gastrointestinal malformations, such as factors related to intrauterine development, ${ }^{55} 56$ surgical treatment, ${ }^{19} 26$ 57-62 compromised bowel function and feeding support, ${ }^{505762}$ and parental social economic status. ${ }^{63}$ We consider this an important issue in future research and suggest prospective registration of potential aetiological factors and neurodevelopment outcomes.

The evidence found in this meta-analysis was primarily based on studies with good quality (74\%). Excluding studies with fair or poor quality did not result in altered conclusions. Risk of publication bias analyses indicated a potential influence of publication bias on the meta-analytical estimations, indicating that these estimations should be interpreted with caution and emphasising importance for preregistration of study protocols.

\section{Limitations}

The findings of the current systematic review and metaanalysis are limited by the use of normative data in the majority of included studies (38 of 47), which does not control for differences in variables such as sex and socioeconomic status. Second, there was heterogeneity in the measures used to assess neurodevelopmental outcome, while some evidence suggests that the Bayley Scales of Infant Development (BSID)-III may overestimate neurodevelopment as compared with the BSID-II. ${ }^{64}$ Third, the tests of subgroup differences on type of malformations and type of outcome domain were limited by partially overlapping subjects across subgroups. However, since related observations tend to decrease variance, this would make the comparison more sensitive for group differences, which were not observed.
Fourth, the quantity of available literature allowed inclusion of only a limited number of potentially moderating aetiological factors in meta-regression and was subject to distinct heterogeneity in terms of construct definitions. Lastly, due to the limited number of studies, our findings for language outcome and the possible influence of moderating factors on all outcomes await replication before a firm conclusion may be drawn.

\section{CONCLUSIONS AND CLINICAL IMPLICATIONS}

In conclusion, this systematic review and meta-analysis presents robust evidence that patients with congenital gastrointestinal malformations are at risk of small-sized to medium-sized impairment in neurodevelopmental outcome, emphasising the need for routine neurodevelopmental screening of these patients.

\section{Author affiliations}

${ }^{1}$ Department of Pediatric Surgery, Amsterdam Reproduction and Development Research Institute, Emma Children's Hospital, Amsterdam UMC, University of Amsterdam and Free University Amsterdam, Amsterdam, The Netherlands ${ }^{2}$ Department of Pediatrics, Emma Neuroscience Group, Amsterdam Reproduction \& Development Research Institute, Emma Children's Hospital, Amsterdam UMC, University of Amsterdam, Amsterdam, The Netherlands

${ }^{3}$ Pediatric Surgery, Princess Maxima Center for Pediatric Oncology, Utrecht, The Netherlands

Acknowledgements The authors would like to thank Faridi $S$ van Etten-Jamaludin (AMC clinical librarian) for her assistance during the construction of search queries for this study.

Contributors DR designed the study, designed data collection, collected data, carried out the initial analyses, drafted the initial manuscript and revised the manuscript. MK supervised data collection and statistical analyses, and critically reviewed the manuscript. LES collected data and carried out the initial analyses. LvdS, EvH and JO conceptualised and designed the study, designed data collection and reviewed the manuscript. All authors approved the final manuscript as submitted and agree to be accountable for all aspects of the work.

Funding The authors have not declared a specific grant for this research from any funding agency in the public, commercial or not-for-profit sectors.

\section{Competing interests None declared.}

Patient consent for publication Not required.

Provenance and peer review Not commissioned; externally peer reviewed.

Data availability statement Data are available upon reasonable request.

Supplemental material This content has been supplied by the author(s). It has not been vetted by BMJ Publishing Group Limited (BMJ) and may not have been peer-reviewed. Any opinions or recommendations discussed are solely those of the author(s) and are not endorsed by BMJ. BMJ disclaims all liability and responsibility arising from any reliance placed on the content. Where the content includes any translated material, BMJ does not warrant the accuracy and reliability of the translations (including but not limited to local regulations, clinical guidelines, terminology, drug names and drug dosages), and is not responsible for any error and/or omissions arising from translation and adaptation or otherwise.

Open access This is an open access article distributed in accordance with the Creative Commons Attribution 4.0 Unported (CC BY 4.0) license, which permits others to copy, redistribute, remix, transform and build upon this work for any purpose, provided the original work is properly cited, a link to the licence is given, and indication of whether changes were made. See: https://creativecommons.org/ licenses/by/4.0/.

\section{ORCID iD}

Daniëlle Roorda http://orcid.org/0000-0001-9740-4957

\section{REFERENCES}

1 EUROCAT. Prevalence Tables (2018) Congenital Malformations [Online], 2018. Available: http://www.eurocat-network.eu/accessprevalencedata/prevalencetables

2 IJsselstijn H, Gischler SJ, Wijnen RMH, et al. Assessment and significance of long-term outcomes in pediatric surgery. Semin Pediatr Surg 2017;26:281-5.

3 Gischler SJ, Mazer P, Duivenvoorden HJ, et al. Interdisciplinary structural follow-up of surgical newborns: a prospective evaluation. J Pediatr Surg 2009;44:1382-9. 
4 Balgi S, Singhal S, Mueller G, et al. Feeding intolerance and poor growth in infants with gastroschisis: longitudinal experience with consecutive patients over thirteen years. J Neonatal Surg 2015;4:42.

5 Versteegh HP, Johal NS, de Blaauw I, Blaauw de I, et al. Urological and sexual outcome in patients with Hirschsprung disease: a systematic review. J Pediatr Urol 2016;12:352-60.

6 Gottrand M, Michaud L, Sfeir R, et al. Motility, digestive and nutritional problems in esophageal atresia. Paediatr Respir Rev 2016;19:28-33.

7 Chumpitazi BP, Nurko S. Defecation disorders in children after surgery for Hirschsprung disease. J Pediatr Gastroenterol Nutr 2011;53:75-9.

8 Gischler SJ, van der Cammen-van Zijp MHM, Mazer P, et al. A prospective comparative evaluation of persistent respiratory morbidity in esophageal atresia and congenital diaphragmatic hernia survivors. J Pediatr Surg 2009;44:1683-90.

9 Stolwijk LJ, Keunen K, de Vries LS, et al. Neonatal surgery for noncardiac congenital anomalies: neonates at risk of brain injury. J Pediatr 2017;182:335-41.

10 Moore SW. Chromosomal and related Mendelian syndromes associated with Hirschsprung's disease. Pediatr Surg Int 2012;28:1045-58.

11 Salinas-Torres VM, Salinas-Torres RA, Cerda-Flores RM, et al. Genetic variants conferring susceptibility to gastroschisis: a phenomenon restricted to the interaction with the environment? Pediatr Surg Int 2018;34:505-14.

12 Nicoletti D, Appel LD, Siedersberger Neto P, et al. Maternal smoking during pregnancy and birth defects in children: a systematic review with meta-analysis. Cad Saude Publica 2014;30:2491-529.

13 Werler MM, Sheehan JE, Mitchell AA. Association of vasoconstrictive exposures with risks of gastroschisis and small intestinal atresia. Epidemiology 2003;14:349-54.

14 Folkerth RD, Habbe DM, Boyd TK, et al. Gastroschisis, destructive brain lesions, and placental infarction in the second trimester suggest a vascular pathogenesis. Pediatr Dev Pathol 2013;16:391-6.

15 Swanson JR, Sinkin RA. Early births and congenital birth defects: a complex interaction. Clin Perinatol 2013:40:629-+.

16 Amrock LG, Starner ML, Murphy KL, et al. Long-Term effects of single or multiple neonatal sevoflurane exposures on rat hippocampal ultrastructure. Anesthesiology 2015;122:87-95.

17 Vutskits L, Davidson A. Update on developmental anesthesia neurotoxicity. Curr Opin Anaesthesiol 2017:30:337-42.

18 Glatz P, Sandin RH, Pedersen NL, et al. Association of anesthesia and surgery during childhood with long-term academic performance. JAMA Pediatr 2017;171:e163470.

19 Tytgat SHAJ, van Herwaarden MYA, Stolwijk LJ, et al. Neonatal brain oxygenation during thoracoscopic correction of esophageal atresia. Surg Endosc 2016;30:2811-7.

20 Bishay M, Giacomello L, Retrosi G, et al. Decreased cerebral oxygen saturation during thoracoscopic repair of congenital diaphragmatic hernia and esophageal atresia in infants. J Pediatr Surg 2011;46:47-51.

21 Neunhoeffer F, Warmann SW, Hofbeck M, et al. Elevated intrathoracic $\mathrm{CO}_{2}$ pressure during thoracoscopic surgery decreases regional cerebral oxygen saturation in neonates and infants-A pilot study. Paediatr Anaesth 2017;27:752-9.

22 Zhou J, Huang W-Q, Li C, et al. Intestinal ischemia/reperfusion enhances microglial activation and induces cerebral injury and memory dysfunction in rats. Crit Care Med 2012:40:2438-48.

23 Hsieh Y-H, McCartney K, Moore TA, et al. Intestinal ischemia-reperfusion injury leads to inflammatory changes in the brain. Shock 2011;36:424-30.

24 Wood SJ, Samangaya RA, Gillham JC, et al. Gastroschisis and the risk of short bowel syndrome: outcomes and counselling. Neonatology 2014;105:5-8.

25 Beers SR, Yaworski JA, Stilley C. Cognitive deficits in school-aged children with severe short bowel syndrome (SBS). Pediatrics 1999;104:770.

26 Chesley PM, Sanchez SE, Melzer L, et al. Neurodevelopmental and cognitive outcomes in children with intestinal failure. J Pediatr Gastroenterol Nutr 2016;63:41-5.

27 Cowan CSM, Dinan TG, Cryan JF. Annual Research Review: Critical windows - the microbiota-gut-brain axis in neurocognitive development. J Child Psychol Psychiatry 2020;61:353-71.

28 Glatz P, Sandin RH, Pedersen NL. Academic performance after anesthesia and surgery during childhood: a large-scale nation-wide study. Anesthesia and Analgesia 2015;120:S289.

29 Gottfredson LS. Why G matters: the complexity of everyday life. Intelligence 1997:24:79-132.

30 Strenze T. Intelligence and socioeconomic success: a meta-analytic review of longitudinal research. Intelligence 2007;35:401-26.

31 Lath NR, Galambos C, Rocha AB, et al. Defective pulmonary innervation and autonomic imbalance in congenital diaphragmatic hernia. Am J Physiol Lung Cell Mol Physiol 2012;302:L390-8.

32 Hollinger LE, Harting MT, Lally KP. Long-Term follow-up of congenital diaphragmatic hernia. Semin Pediatr Surg 2017;26:178-84.

33 Lin N, Antiel R, Waqar L. Brain maturation and neurodevelopmental outcomes in infants with congenital diaphragmatic hernia. Annals of Neurology 2016;80:\$400-2.

34 Schiller RM, Madderom MJ, Reuser JJCM, et al. Neuropsychological follow-up after neonatal ECMO. Pediatrics 2016;138:138.

35 ljsselstijn H, van Heijst AFJ. Long-Term outcome of children treated with neonatal extracorporeal membrane oxygenation: increasing problems with increasing age. Semin Perinatol 2014;38:114-21.
36 Shamseer L, Moher D, Clarke M, et al. Preferred reporting items for systematic review and meta-analysis protocols (PRISMA-P) 2015: elaboration and explanation. BMJ 2015;350:g7647

37 Covidence systematic review software, veritas health innovation, Melbourne, Australia Available: www.covidence.org

38 Wells GA, Shea B, Higgins JP, et al. Checklists of methodological issues for review authors to consider when including non-randomized studies in systematic reviews. Res Synth Methods 2013:4:63-77.

39 Viswanathan M, Ansari MT, Berkman ND. AHRQ Methods for Effective Health Care Assessing the Risk of Bias of Individual Studies in Systematic Reviews of Health Care Interventions. Methods Guide for Effectiveness and Comparative Effectiveness Reviews. Rockville (MD: Agency for Healthcare Research and Quality (US), 2008.

40 Wan X, Wang W, Liu J, et al. Estimating the sample mean and standard deviation from the sample size, median, range and/or interquartile range. BMC Med Res Methodol 2014; 14:135.

41 Luo D, Wan X, Liu J, et al. Optimally estimating the sample mean from the sample size, median, mid-range, and/or mid-quartile range. Stat Methods Med Res 2018;27:1785-805.

42 Cohen J. Statistical power analysis for the behavioral science. 2nd ed. Erlbaum, Hillsdale, NJ, 1988

43 Higgins JPT, Thompson SG. Quantifying heterogeneity in a meta-analysis. Stat Med 2002;21:1539-58

44 Egger M, Davey Smith G, Schneider M, et al. Bias in meta-analysis detected by a simple, graphical test. BMJ 1997;315:629-34.

45 Stolwijk LJ, Lemmers PM, Harmsen M, et al. Neurodevelopmental outcomes after neonatal surgery for major noncardiac anomalies. Pediatrics 2016;137:e20151728.

46 Bevilacqua F, Morini F, Valfrè L, et al. Surgical gastrointestinal anomalies including diaphragmatic hernia: does type of anomaly affect neurodevelopmental outcome? Am J Perinatol 2014;31:175-80

47 Kubota A, Nose K, Yamamoto E, et al. Psychosocial and cognitive consequences of major neonatal surgery. J Pediatr Surg 2011;46:2250-3.

48 South AP, Marshall DD, Bose CL, et al. Growth and neurodevelopment at 16 to 24 months of age for infants born with gastroschisis. J Perinatol 2008;28:702-6.

49 Elsinga RM, Roze E, Van Braeckel KNJA, et al. Motor and cognitive outcome at school age of children with surgically treated intestinal obstructions in the neonatal period. Early Hum Dev 2013;89:181-5.

50 van Eijck FC, van Vlimmeren LA, Wijnen RMH, et al. Functional, motor developmental, and long-term outcome after the component separation technique in children with giant omphalocele: a case control study. J Pediatr Surg 2013:48:525-32.

51 Borges Nery P, Camelo Júnior JS. PO-0445 Neurobehavioral Assessment Of Late Preterm And Full-term Infants: A Preliminary Study. Arch Dis Child 2014;99:A39 1.1-A391.

52 Schermann L, Sedin G. Cognitive function at 10 years of age in children who have required neonatal intensive care. Acta Paediatr 2004;93:1619-29.

53 Ziborova M, Keshishian E, Sakharova E. Delayed neurodevelopmental outcomes in pre-/early school-aged VPT/VLBW children. Journal of Maternal-Fetal and Neonatal Medicine 2014:27:263.

54 Twilhaar ES, Wade RM, de Kieviet JF, et al. Cognitive outcomes of children born extremely or very preterm since the 1990s and associated risk factors: a meta-analysis and meta-regression. JAMA Pediatr 2018;172:361-7.

55 Grieco J, Pulsifer M, Seligsohn K, et al. Down syndrome: cognitive and behavioral functioning across the lifespan. Am J Med Genet C Semin Med Genet 2015;169:135-49.

56 Holbrook BD. The effects of nicotine on human fetal development. Birth Defects Res $C$ Embryo Today 2016;108:181-92.

57 Aite L, Bevilacqua F, Zaccara A, et al. Short-Term neurodevelopmental outcome of babies operated on for low-risk esophageal atresia: a pilot study. Dis Esophagus 2014;27:330-4.

58 Bevilacqua F, Ravà L, Valfrè L, et al. Factors affecting short-term neurodevelopmental outcome in children operated on for major congenital anomalies. J Pediatr Surg 2015;50:1125-9.

59 Harmsen WJ, Aarsen FJ, van der Cammen-van Zijp MHM, et al. Developmental problems in patients with oesophageal atresia: a longitudinal follow-up study. Arch Dis Child Fetal Neonatal Ed 2017;102:F214-9.

60 Kato T, Kanto K, Yoshino H, et al. Mental and intellectual development of neonatal surgical children in a long-term follow-up. J Pediatr Surg 1993;28:123-9.

61 Ludman L, Spitz L, Lansdown R. Developmental progress of newborns undergoing neonatal surgery. J Pediatr Surg 1990;25:469-71.

62 Danzer E, Gerdes M, D'Agostino JA, et al. Patient characteristics are important determinants of neurodevelopmental outcome during infancy in giant omphalocele. Early Hum Dev 2015;91:187-93.

63 Clearfield MW, Niman LC. Ses affects infant cognitive flexibility. Infant Behav Dev 2012;35:29-35.

64 Sharp M, DeMauro SB. Counterbalanced comparison of the BSID-II and Bayley-III at eighteen to twenty-two months corrected age. J Dev Behav Pediatr 2017;38:322-9.

65 Bouman NH, Koot HM, Hazebroek FW. Long-Term physical, psychological, and social functioning of children with esophageal atresia. J Pediatr Surg 1999;34:399-404. 
66 Burnett AC, Gunn JK, Hutchinson EA, et al. Cognition and behaviour in children with congenital abdominal wall defects. Early Hum Dev 2018;116:47-52.

67 Costerus S, Vlot J, van Rosmalen J, et al. Effects of neonatal thoracoscopic surgery on tissue oxygenation: a pilot study on (neuro-) monitoring and outcomes. Eur J Pediatr Surg 2019;29:166-72.

68 Doberschuetz N, Dewitz R, Rolle U, et al. Follow-Up of children with gastrointestinal malformations and postnatal surgery and anesthesia: evaluation at two years of age. Neonatology 2016;110:8-13.

69 Faugli A, Bjørnland K, Emblem R, et al. Mental health and psychosocial functioning in adolescents with esophageal atresia. J Pediatr Surg 2009:44:729-37.

70 Giúdici L, Bokser VS, Maricic MA, et al. Babies born with gastroschisis and followed up to the age of six years faced long-term morbidity and impairments. Acta Paediatr 2016;105:e275-80

71 Giúdici L, Bokser VS, Maricic MA, et al. Babies born with Gastroschisis and followed up to the age of six years faced long-term morbidity and impairments. Acta Paediatr 2016;105:e275-80.

72 Gorra AS, Needelman H, Azarow KS, et al. Long-Term neurodevelopmental outcomes in children born with gastroschisis: the tiebreaker. J Pediatr Surg 2012:47:125-9.

73 Harris EL, Hart SJ, Minutillo C, et al. The long-term neurodevelopmental and psychological outcomes of gastroschisis: a cohort study. J Pediatr Surg 2016:51:549-53.

74 Hijkoop A, IJsselstijn H, Wijnen RMH, et al. Prenatal markers and longitudinal follow-up in simple and complex gastroschisis. Arch Dis Child Fetal Neonatal Ed 2018;103:F126-31.

75 Luttikhuizen dos Santos ES, de Kieviet JF, Königs M, et al. Predictive value of the Bayley scales of infant development on development of very preterm/very low birth weight children: a meta-analysis. Early Hum Dev 2013:89:487-96.

76 Kumari V, Joshi P, Dhua AK, et al. Developmental status of children operated for esophageal atresia with or without tracheoesophageal fistula along with maternal stress, their quality of life, and coping abilities at AllMS, new Delhi. Eur J Pediatr Surg 2019;29:125-31.

77 Laing S, Walker K, Ungerer J, et al. Early development of children with major birth defects requiring newborn surgery. J Paediatr Child Health 2011;47:140-7.

78 Ludman L, Spitz L, Lansdown R. Intellectual development at 3 years of age of children who underwent major neonatal surgery. J Pediatr Surg 1993;28:130-4.

79 Maheshwari R, Trivedi A, Walker K, et al. Retrospective cohort study of long-gap oesophageal atresia. J Paediatr Child Health 2013;49:845-9.

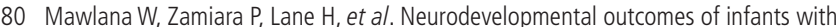
esophageal atresia and tracheoesophageal fistula. J Pediatr Surg 2018;53:1651-4.
81 Minutillo C, Rao SC, Pirie S, et al. Growth and developmental outcomes of infants with gastroschisis at one year of age: a retrospective study. J Pediatr Surg 2013;48:1688-96.

82 Moran MM, Gunn-Charlton JK, Walsh JM, et al. Associations of neonatal noncardiac surgery with brain structure and neurodevelopment: a prospective case-control study. J Pediatr 2019;212:93-101.

83 More K, Rao S, McMichael J, et al. Growth and developmental outcomes of infants with Hirschsprung disease presenting in the neonatal period: a retrospective study. J Pediatr 2014;165:73-7.

84 Newton LE, Abdessalam SF, Raynor SC, et al. Neurodevelopmental outcomes of tracheoesophageal fistulas. J Pediatr Surg 2016;51:743-7.

85 Payne NR, Gilmore L, Svobodny S, et al. A cross-sectional, case-control follow-up of infants with gastroschisis. J Neonatal Perinatal Med 2010;3:207-15.

86 Plummer EA, Wang Q, Larson-Nath CM, et al. Body composition and cognition in preschool-age children with congenital gastrointestinal anomalies. Early Hum Dev 2019;129:5-10.

87 Sirichaipornsak S, Jirapradittha J, Kiatchoosakun P, et al. Neurodevelopmental outcomes of children with gastroschisis at university hospital in northeast Thailand. Asian Biomedicine 2011:5:861-6.

88 So S, Patterson C, Gold A, et al. Early neurodevelopmental outcomes of infants with intestinal failure. Early Hum Dev 2016;101:11-16.

89 So S, Patterson C, Evans C, et al. Motor proficiency and generalized self-efficacy toward physical activity in children with intestinal failure. J Pediatr Gastroenterol Nutr 2019;68:7-12

90 So S, Patterson C, Gold A, et al. Neurodevelopmental outcomes of infants with intestinal failure at 12 and 26 months corrected age. Early Hum Dev 2019;130:38-43

91 South AP, Marshall DD, Bose CL, et al. Growth and neurodevelopment at 16 to 24 months of age for infants born with Gastroschisis. J Perinatol 2008;28:702-6.

92 van den Hondel D, Sloots CEJ, Gischler SJ, et al. Prospective long-term follow up of children with anorectal malformation: growth and development until 5years of age. J Pediatr Surg 2013:48:818-25.

93 van den Hondel D, Aarsen FK, Wijnen RMH, et al. Children with congenital colorectal malformations often require special education or remedial teaching, despite normal intelligence. Acta Paediatr 2016;105:e77-84.

94 Walker K, Halliday R, Badawi N, et al. Early developmental outcome following surgery for oesophageal atresia. J Paediatr Child Health 2013:49:467-70.

95 Walker K, Loughran-Fowlds A, Halliday R, et al. Developmental outcomes at 3 years of age following major non-cardiac and cardiac surgery in term infants: a populationbased study. J Paediatr Child Health 2015;51:1221-5. 